\title{
Secondary Stress Induced Central Serous Chorioretinopathy in Bamako: Report of Two Cases
}

\author{
Rodrigue Romuald Elien Gagnan Yan Zaou Tou* (), Adama Guindo, Mahamat Adam Dicko, \\ Mohamed Kole Sidibe, Aly Sylla, Modibo Diarra, Mohamed Inoussa Lamine Abdoulaye, \\ Nagnan Chieck Rahim Diabate, Hamadoun Diallo
}

Institute of African Tropical Ophthalmology, University of Sciences and Technology of Bamako, Bamako, Mali

Email: *rodrigueelien@yahoo.fr

How to cite this paper: Elien Gagnan Yan Zaou Tou, R.R., Guindo, A., Dicko, M.A., Sidibe, M.K., Sylla, A., Diarra, M., Abdoulaye, M.I.L., Diabate, N.C.R. and Diallo, H. (2020) Secondary Stress Induced Central Serous Chorioretinopathy in Bamako: Report of Two Cases. Open Journal of Ophthalmology, 10, 268-275.

https://doi.org/10.4236/ojoph.2020.104029

Received: July 30, 2020

Accepted: October 26, 2020

Published: October 29, 2020

Copyright $\odot 2020$ by author(s) and Scientific Research Publishing Inc. This work is licensed under the Creative Commons Attribution International License (CC BY 4.0).

http://creativecommons.org/licenses/by/4.0/

\begin{abstract}
Introduction: Idiopathic central serous chorioretinopathy (ICSC) is characterized by the buildup of fluid leading to circumscribed elevation of the retina within the posterior pole. This condition affects young people between the ages of 20 - 50 years. The disease is seen predominantly in men as compared to women. We report the cases of two (02) patients received in consultation at IOTA-Teaching Hospital between July 2019 and February 2020. Case Presentation: We report two cases of Idiopathic stress central serous chorioretinopathy. The first case is a 37-year-old man that we received in consultation for visual acuity decrease from a sudden installation for 1 hour. The clinical and paraclinical arguments permitted us to retain the diagnosis of Idiopathic stress central serous chorioretinopathy. The patient benefited from laser treatment and the clinical evolution was good. The second case is a 42-year-old man, who consulted for a sudden reduction of visual acuity that had been evolving for 3 weeks. The clinical and paraclinical contexts were in favour of the diagnosis of Idiopathic stress central serous chorioretinopathy. The patient was treated with spironolactone. The clinical evolution was favourable. Conclusion: Our study confirms the existence of central serous chorioretinopathy (CSC) in Black African patients. Studies show the connection between CSC and stress.
\end{abstract}

\section{Keywords}

Stress, Central Serous Chorioretinopathy, Fluorescein Angiography, Bamako

\section{Introduction}

Von Graefe, in 1866, was the first to describe a disease of the macula with recur- 
rent serous detachment and to name it recurrent central retinitis [1]. In 1945, Bennet Klein and Maumenee were the first to postulate that the subretinal fluid was derived from choriocapillaris, through the retinal pigment epithelium (RPE) [2] [3]. Gass and et al, in 1966, provided the classic description of the pathogenesis and clinical features of this condition and term of Idiopathic Central Serous Choroidopathy [4]. Later, the name Central Serous Chorioretinopathy is now accepted because the disease involves both the choroid and retina [5]. The Central Serous Chorioretinopathy is the collection of fluid between the RPE and the neurosensory retina [5]. There are two forms: acute and chronic [5]. The Central Serous Chorioretinopathy is characterized by a functional macular and clinical syndrome of serous retinal detachment, most commonly found in the macular region. Its diagnosis is based on angiographic criteria. The literature reported many risk factors of Central Serous Chorioretinopathy such as: local or systemic corticosteroid therapy, Cushing's disease and pregnancy by increased production of endogenous cortisol; other risk factors independent are Type A personality, antipsychotic medication, and psychological stress [6] [7].

In Europe, in 2018, the Central Serous Chorioretinopathy was the 4th most common retinal pathology after age-related macular degeneration, diabetic retinopathy, and occlusion of the retinal vein branch. Its incidence is estimated at 9.9 cases per 100,000 men and 1.7 cases per 100,000 women [8].

In Africa, the prevalence of Central Serous Chorioretinopathy is unknown and the published data are disparate [9] [10] [11] [12] [13]. The first description of secondary stress central serous chorioretinopathy goes to the Togolese authors. The rarity of reports cases of the Secondary Stress Central Serous Chorioretinopathy leads to the realization of this study whose purpose is to contribute to the description of Stress-induced Central Serous Chorioretinopathy.

\section{Methodology}

This is the report of two clinical cases received in the IOTA-Teaching Hospital consultation boxes between June 2019 and February 2020. All methods were approved by our institution's research committee. History, physical examination, and imaging data were obtained from electronic medical records of the patient in question.

\section{Patients and Observation}

\subsection{Case 1}

This is a 37-year-old male admitted for Sudden Visual Acuity Decrease for 1 hour ago. The analysis of his pathological antecedents has no found the notion of local or systemic corticosteroid therapy and antipsychotic medications. At presentation, in the right eye, the distant visual acuity was $1 / 10$ Snellen line. On fundus examination, there was a serous neuroretinal detachment of macular localization measuring about 4 papillary diameters (Figure 1(a)). In the left eye, distant visual acuity was 10/10 Snellen line, the anterior sergment and fundus 
examinations were found to be normal (Figure 1(b)). In the right eye, Fluorescein angiography showed "leakage points" like "vapor jet" in the form of abnormal hyperfluorescence with increasing crescendo intensity and localized in serous retinal detachment. Subsequently (Figure 2(a) and Figure 2(b)), the etiological investigation revealed in our patient a state of extreme anguish related to the survival of his only child admitted to pediatric intensive care with respiratory assistance for 1 week.

The discomfort resulting from the decrease in visual acuity motivated the therapeutic option by photo coagulation by an argon laser at the extrafoveal leakage point with impacts of 200 microns, for a period of 100 milliseconds and a power of 100 milliwatts. At one week, distant visual acuity was up to 5/10 Snellen line in the right eye. At the $3 \mathrm{rd}$ week, there is no serous retinal detachment at the fundus examination of the right eye and angiography control showed no recurrence, no new thrust, no long-term complication, with a distant visual acuity of 10/10 Snellen line in both eyes then referred to the psychologist for psychological support

\subsection{Case 2}

This is a 42-year-old male business agent of the orange company, very energetic

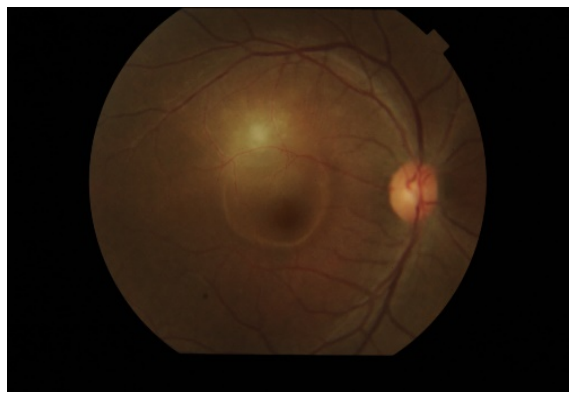

(a)

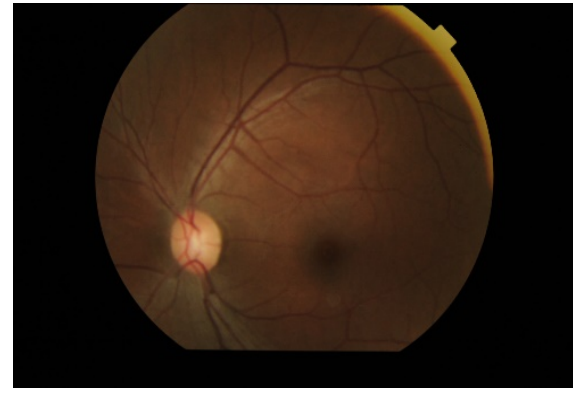

(b)

Figure 1. Colour images of the fundus: a serous retinal macular detachment in the right eye (a) and macular atrophy in the left eye (b).

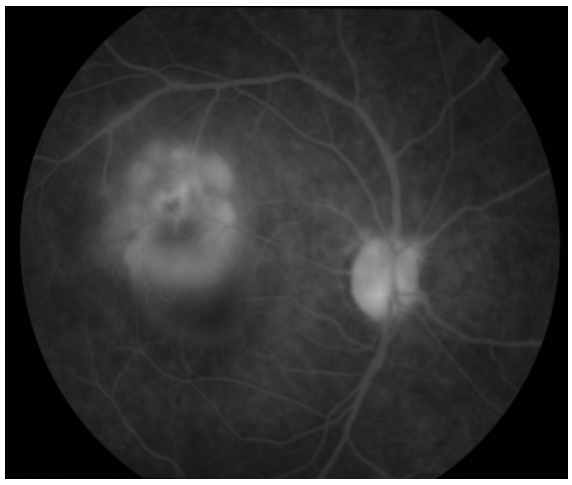

(a)

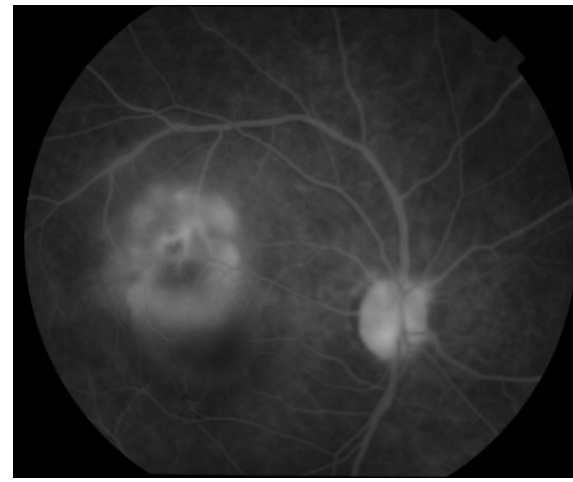

(b)

Figure 2. Late time images of fluorescein angiography: showing multiple hyperfluorescent areas in right eyes of crescendo intensity. 
and hyperactive, referred from the MOPTI reference health center for the investigation of Sudden Visual Acuity Decrease evolving for 3 weeks without improvement, associated with an important gene, metamorphopsia, and central scotomas. MOPTI IS one of the conflict region of northern Mali, occupied by terrorism "Jihadists". The analysis of his pathological antecedents has no found the notion of local or systemic corticosteroïde therapy and the antipsychotic medications. At presentation, in the right eye, the distant visual acuity was 3/10. On fundus examination, there was a serous neuroretinal detachment of macular localization measuring about 4 papillary diameters (Figure 3(a)). In the left eye, distant visual acuity was 10/10 Snellen line, the anterior segment and fundus examinations were found to be normal (Figure 3(b)). In the right eye, Fluorescein angiography did not show the «leakage points» (Figure 4). Contrary, the image of radial Macula OCT confirms the diagnosis by showing the serous detachment of the neuroretina. Subsequently (Figure 5), the etiological investigation with the participation of the psychologist revealed in our patient the type-A personality associated with a state of extreme anxiety and emotion due to the uncertainty about his professional activities. He was put on spironolactone tablet $50 \mathrm{mg}$ at a rate of 1 tablet per day for 1 month then referred to the psychologist for psychological support. The resorption of the subretinal liquid was slow and progressive to be complete by the 2 nd month of treatment.

\section{Discussion}

The first case of Idiopathic Central Serous Chorioretinopathy in African peoples was described by Ballo K P et al. in 1996 at Lomé [9] followed by Fanny et al. in 2008 at Ivory Coast [10] and Chrabi et al. in 2017 at Morocco [14]. Each of these authors confirmed the relationship between stress and Idiopathic Central Serous Chorioretinopathy through significant statistical tests (notably Fanny et al. and Chrabi et al.). We think, as do other authors [9] [10] [11], that race cannot be considered a significant predictor factor of Idiopathic Central Serous Chorioretinopathy.

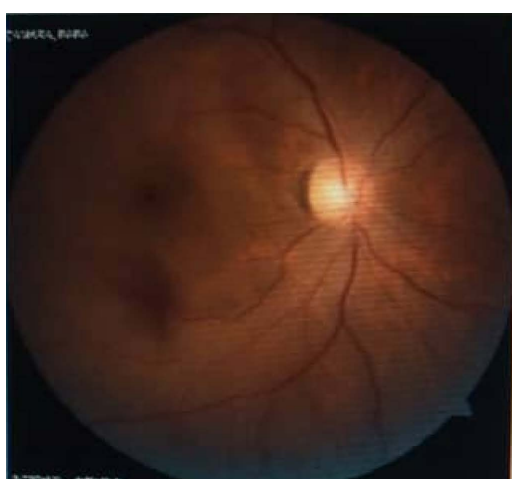

(a)

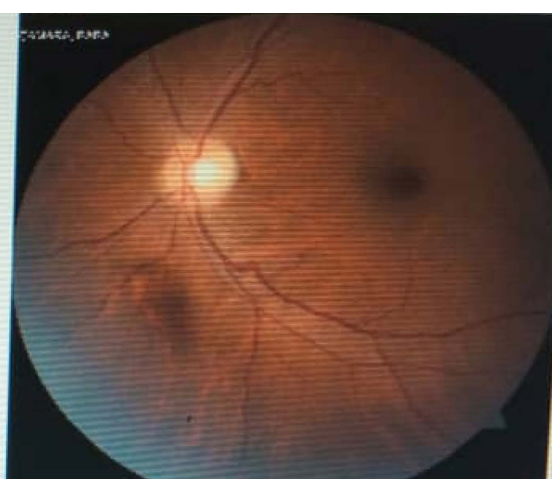

(b)

Figure 3. Colour images of the fundus: a serous retinal macular detachment in the right eye (a) and macular atrophy in the left eye (b) and alteration of pigment epithelium in both eye. 


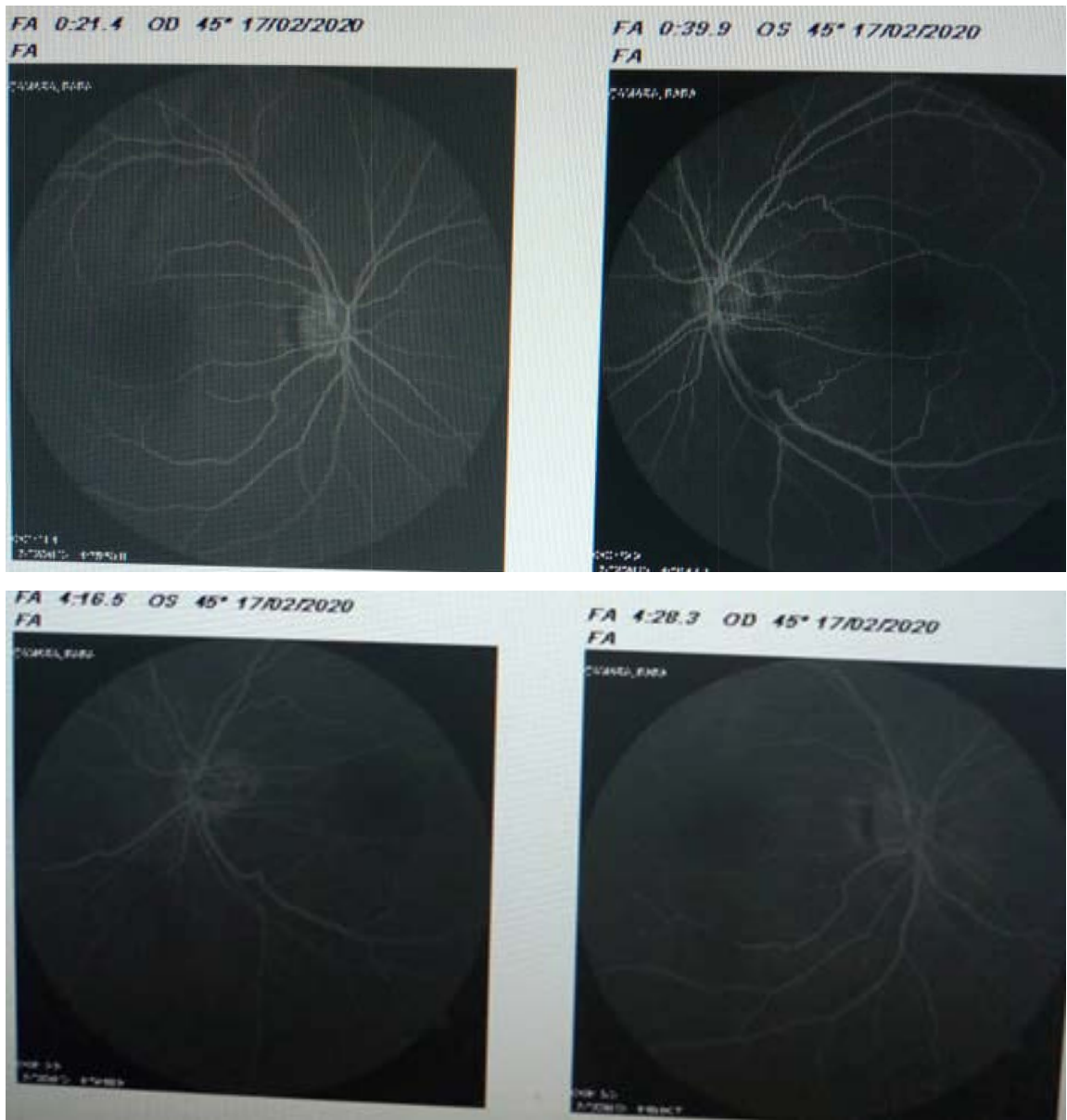

Figure 4. Precoce and late time images of fluorescein angiography: No point of leak.

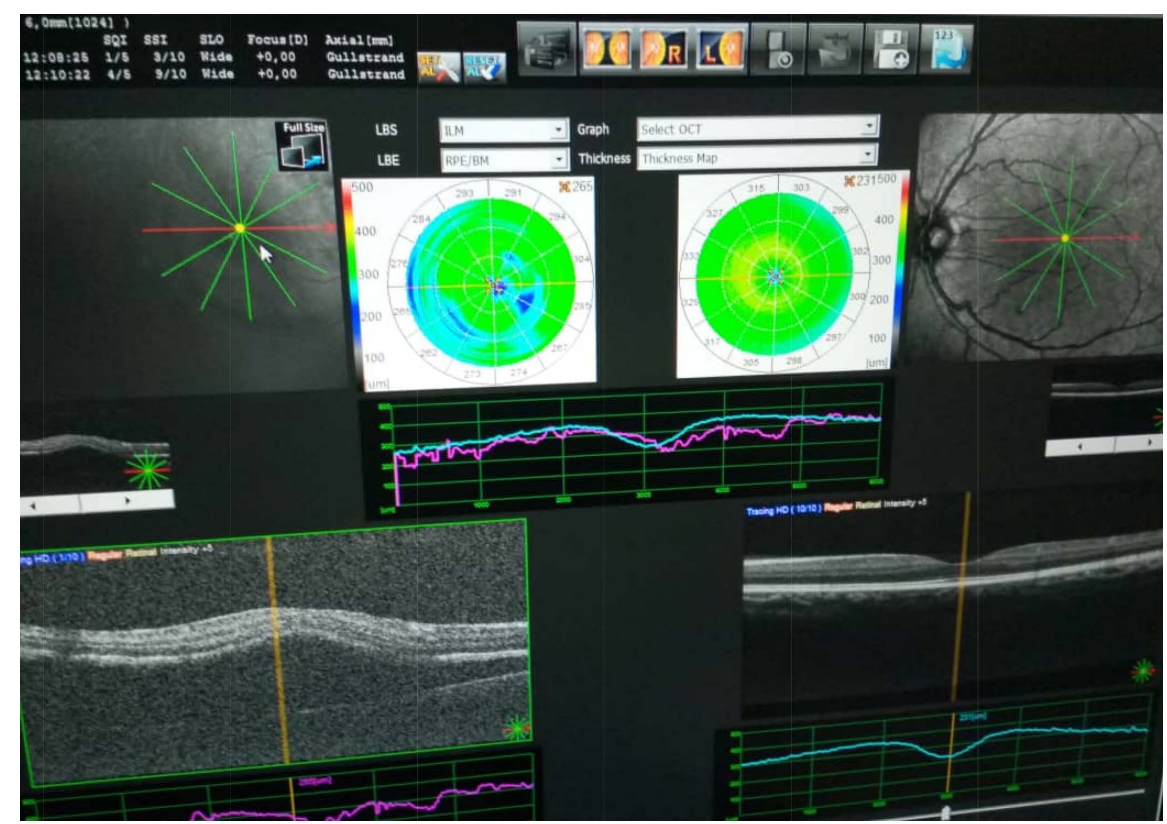

Figure 5. Images of Radial Macula OCT: showing an unusual serous detachment of the macula extending extensively towards the temporal the serous detachment of neuroretina in right eye. 
Our patients are both males, in accordance with current literature attesting to the high frequency of this disease in the male gent [5] [6] [7] [8]. The rarity of this pathology in Black Africa is linked to the difficulties of access to diagnostic examinations equipment, which remain rare in Black Africa, especially in conflict zones.

The age of our patients was in the 30 - 50 age range, consistent with earlier work in Europe [5] [6] [7] [8] and Africa [9]-[14]. For it is undeniable that Idiopathic Central Serous Chorioretinopathy reaches young men more often. However, some authors in America reported the suspicion of Idiopathic Central Serous Chorioretinopathy cases among girls aged 12-year old in 2012 [15].

The risk factors in favor of idiopathic origin found in our patients were: stress, extreme anxiety, insomnia, Type-A personality. Similar to the observations of European [5] [6] [7] [8] and African [9] [10] [11] authors especially that of Ivory Coast [10].

In general, the main risk factors for CRC in Africa reported in the literature are:

23 cases of Idiopathic Central Serous Chorioretinopathy post-stress including 2 in Lomé [9], 2 in Burkina Faso [11], 6 in Ivory Coast [10] and 13 in Morocco [14].

1 case of Central Serous Chorioretinopathy after the renal transplant in 2005 in Tunisia [16].

1 case of Central Serous Chorioretinopathy during systemic corticosteroid therapy in 2008 in Burkina Faso [11].

1 case of Central Serous Chorioretinopathy during systemic corticosteroid therapy in 2014 in Tunisia [13].

1 case of Central Serous Chorioretinopathy in a pregnant woman in 2014 in Morocco [17].

2 cases of Central Serous Chorioretinpathy after epidural corticosteroid injection in Morocco in 2015 and 2016 [12] [14].

As for functional signs, the sudden decrease of visual acuity and metamorphosis were present in our patients. Like the corroboree the literature data [5]-[14].

The detachment of the neuroretina by the accumulation of serous fluid observed at the fundus in our patients is very characteristic to the Central Serous Chorioretinopathy.

Fluorescein angiography confirms the diagnosis by showing the presence or absence of leakage points [5] [6] [7] [8]. Leak points were only seen at Fluorescein angiography in our first case.

Further exploration of ophthalmological imaging of confirmation diagnosis, no less important, is the OCT. These newer imaging techniques help in the improved morphological analysis and hence better elucidation of the pathophysiology and management of CSC as well as detection of the occult form [5] [6] [7].

On the other hand, Lahousen T. et al. showed in 2015 that stressful life events 
and certain personality traits such as aggression have been shown to be associated with increased levels of both catecholamines and corticosteroids [18].

\section{Conclusion}

There is no longer any doubt that the Central Serous Chorioretinopathy is also found in African black and its etiology is largely dominated by stress and anxiety, especially related to the military-political and economic crises that are shaking the African continent today. Given the relevance of the subject, it would be desirable to carry out a meta-analysis of all aspects of this affection on the African continent, at least in the melanoderm.

\section{Conflicts of Interest}

The authors declare no conflicts of interest regarding the publication of this paper.

\section{References}

[1] Von Graefe, A. (1866) Ueber zentrale recidivierende Retinitis. Graefe's Archives for Clinical and Experimental Ophthalmology, 12, 211-215.

[2] Bennett, G. (1955) Central Serous Retinopathy. British Journal of Ophthalmology, 39, 605-618. https://doi.org/10.1136/bjo.39.10.605

[3] Maumenee, A.E. (1965) Sympsium on Macular Diseases: Clinical Manifestations. American Academy of Ophthalmology and Otolaryngology, 69, 605-613.

[4] Gass, J.D. and Norton, E.W.D. (2003) Serous Detachment of the Retinal Pigment Epithelium. Retina, 23, 990-1015.

[5] Prakash, G., Chauhan, N., Jain, S. and Satsangi, S.K. (2003) Central Serous Chorioretinopathy: A Review of the Literature. The Asia-Pacific Journal of Ophthalmology, 2, 104-110. https://doi.org/10.1097/APO.0b013e31829069ee

[6] Haimovici, R., Koh, S., Gagnon, D.R., Lehrfeld, T. and Wellik, S. Central Serous Chorioretinopathy Case-Control Study Group (2004) Risk Factors for Central Serous Chorioretinopathy: A Case-Control Study. Ophthalmology, 111, 244-249. https://doi.org/10.1016/j.ophtha.2003.09.024

[7] Liu, B., Deng, T., Zhang, J. (2016) Risk Factors for Central Serous Chorioretinopathy: A Systematic Review and Meta-Analysis. Retina, 36, 9-19. https://doi.org/10.1097/IAE.0000000000000837

[8] Wang, M., Munch, I.C., Hasler, P.W., Prünte, C. and Larsen, M. (2008) Central Serous Chorioretinopathy. Acta Ophthalmologica, 86, 126-145. https://doi.org/10.1111/j.1600-0420.2007.00889.x

[9] Balo, K.P. and Mihluedo, H. (1996) Choriorétinopathie séreuse centrale idiopathique. À propos de deux cas observés au Togo. Médecine Tropicale, 56, 381-383.

[10] Fanny, A., Gbé, K., Coulibaly, F., Bérété-Coulibaly, R., Boni, S., Ouattara, A. and Kéita, M. (2008) Choriorétinopathie séreuse centrale: étude de 6 cas observés à Abidjan entre 2003 et 2005, rôle évoqué de la crise ivoirienne. Journal Français d Ophtalmologie, 31, 1018-1024. https://doi.org/10.1016/S0181-5512(08)74749-1

[11] Diallo, J.W., Daboue, A., Boni, S., Ouedraogo, M. and Sanfo, O. (2008) Resultats de la prise en charge des trois premiers cas de chorioretinopathie sereuse central (CRSC) par photocoagulationau Burkina Faso à propos de 3 cas. Revue Internation- 
al des Sciences Médicales, 10, 51-56.

[12] Tliba, A., Boussetta, N., Metoui, L., Gharsallah, I., Ajili, F., Louzir, B. and Othmani, S. (2016) La choriorétinopathie séreuse centrale secondaire à l'infiltration péridurale de corticoïdes. La Tunisie Medicale, 94, 166.

[13] Chaker, N., ChebiL, A., Kort, F., Rim, B. and El Matri, L. (2014) Chorioretinite sereuse centrale atypique chez un patient traite par corticotherapie systemique au long cours. La Tunisie Medicale, 92, 590-591.

[14] Chraibi, F., Benatiya Andaloussi, I., Abdellaoui, M. and Tahri, A. (2017) La Choriorétinopathie séreuse centrale et le stress. Journal de la société Marocaine d Ophtalmologie, 26, 9-11.

[15] Velazquez-Martin, J.P., Fulda, E., Domville, D., Graus-Wiechus, F. and Krema, H. (2012) Presumed Idiopathic Central Serous Chorioretinopathy in a 12 Year Old Girl. Case Reports in Ophthalmology, 3, 5-10. https://doi.org/10.1159/000335894

[16] Kamoun, R., Zhioua, R., Beltaief, O., Boussen, I. and Meddeb Ouertani, A. (2005) Choriorétinite séreuse centrale chez un patient greffé du rein: À propos d'un cas. Journal Français d' Ophtalmologie, 28, 51-54.

https://doi.org/10.1016/S0181-5512(05)81025-3

[17] Hafidi, Z. and Daoudi, R. (2014) Rare Cause of Decrease in Visual Acuity in Pregnancy. Pan African Medical Journal, 17, Article 86. https://doi.org/10.11604/pamj.2014.17.86.3913

[18] Lahousen, T., Painold, A., Luxenberger, W., Schienle, A., Kapfhammer, H.P. and Ille, R. (2015) Psychological Factors Associated with Acute and Chronic Central Serous Chorioretinopathy. Nordic Journal of Psychiatry, 70, 1-7. https://doi.org/10.3109/08039488.2015.1041156 